$\xi=2$ 줄

\title{
Evaluation of maxillary anterior endodontically treated teeth restored with different types of crowns
}

\author{
Mohammed M Al Moaleem ${ }^{1 *}$, Abdulrahman A Mobaraky ${ }^{2}$, Hassan A Madkhali ${ }^{2}$, Muneera R Gohal ${ }^{2}$, Amna M \\ Mobaraki $^{2}$, Ebithag H Adawi ${ }^{3}$, Fahad M Kariri ${ }^{2}$, Musab H Judayba ${ }^{2}$, Mosaab M Qohal ${ }^{4}$, Nabiel Alghazali ${ }^{5}$ \\ ${ }^{1}$ Department of Prosthetic Dental Science, College of Dentistry, Jazan University, Jazan, KSA \\ ${ }^{2}$ Dental Interns, College of Dentistry, Jazan University, Jazan, KSA \\ ${ }^{3}$ General Practitioner, Ministry of Health, Jazan, KSA \\ ${ }^{4}$ Final Year Dental Student, College of Dentistry, Jazan University, Jazan, KSA \\ ${ }^{5}$ Department of Prosthodontics, College of Dentistry, Aleppo University, Aleppo, Syria \\ *Corresponding author E-mail: drmoaleem2014@gmail.com
}

\begin{abstract}
Statement of the problem: restoring endodontically treated teeth (ETT) is one of the major treatments provided by a dentist. Glass fiber posts (GFP) showed good clinical performance during last few years.

Aim of the study; to assess and compare the clinical as well as the radiographic performance of different types of ceramic crown systems used in restoration of maxillary anterior teeth over a cemented GFP and composite resin core.

Materials and methods: 50 ETT with GFP were included in this study. These teeth were divided into four gropes (composite resin.

Porcelain fused to metal (PFM), e. max and zirconia restorations). Both the clinical and radiographic assessments were done for the restoration at a period of one week, 3, 6, 9, and 12 months after composite build up and crown's cementations. All data were registered and analyzed by SPSS program using percentages and Kaplan-Meyer analysis. Fisher's exact test was used for categorical values while logrank test was used for descriptive statistical analysis.

Results: the clinical assessment showed no changes in the one week, 3 and 6 months in the four groups. While during the 9 and 12 months, a movement of the crown margin under finger pressure was present in one case, loss or retention in 2 cases of zirconia, the periodontal status with violation of biological width was present in one case of PFM and finally the color changes were obvious in one case of PFM and 2 cases of composite restoration. All the restorations in the four groups had no radiographic changes in the one week and three-month assessments. While during six-month follow-up, a loosed of retention in one case of the zirconia crown was detected. At the 9 and 12 months, two cases showed recurrent caries at the cervical margin of the composite restoration, cases with periapical infection and other with loss of retention of the post were recorded in the PFM restoration.

Conclusion: e. Max and zirconia all ceramic crowns showed better clinical and radiographic performance than the PFM and composite restorations over 12 months recall.
\end{abstract}

Keywords: Clinical; Endodontically Treated Teeth; Follow-Up; Glass Fiber-Reinforced Posts; Radiographic; Maxillary Teeth

\section{Introduction}

The endodontically treated teeth (ETT) for anterior teeth traditionally were restored with post and core as a foundation for the permanent restoration to replace the loosed coronal portion (Gutma 1992, P. 458; Cohen BI et al, 1996, p. 487; Preethi \& Kala, 2008, p. 162).

Although the need for crown coverage for an ETT is still convective, and no recent clinical study is a valuable to confirm the indications given in the literature (Sorenson JP et al, 1984, p.780, Paul \& Scharer, 1998, p. 513) [4-5]. However, ETT and post placement are regarded as major causes of root fracture, as a protective measure extra-coronal coverage has been thought high recommended (Sorenson JP et al, 1984, p. 780; Paul \& Scharer, 1998, p. 513; Fuss Z et al 1, 2001, p. 46).

For several years, ETT for maxillary anterior teeth with extensive loss of tooth structure have traditionally been restored using cast or fabricated metal posts as the core reconstruction under crowns in most of the cases (King PA et al, 2003, p. 785).
Recently, several new types of post material have been introduced, including carbon fiber, GFP, fiber-reinforced composite posts, etc (Preethi \& Kala, 2008, p. 162). The GF supported resin dowel systems were introduced in early of 1992. The cores contain of unidirectional glass fibres embedded in a resin matrix that strengthens the cores without compromising the modulus of elasticity. Other advantages of GFP are the ability to distribute stress over a broad surface area, increasing the load threshold at which the core begins to show evidence of micro-fractures. GFP cores are reported to reduce the risk of tooth fractures and display higher survival rates compared to teeth restored with other types of posts (Usumz A et al, 2004, p. 163). When the GFP with composite core is used in single rooted maxillary anterior teeth, it associated with a higher success rate in restoration of ETT (Preethi \& Kala, 2008, p. 162; Grandian S et al, 2005, p. 399).

For many years, PFM crowns have represented the most widely used restorative technique in maxillary anterior teeth. This popularity may have attributed to the clinical longevity and accepted aesthetics of the restoration (Trautmann G et al, 2000, p. 719.

The introduction of improved all-ceramic systems makes it possible to achieve maximum aesthetics allied with the necessary me- 
chanical properties to withstand functional stresses and retention (Kato H et al, 1996, p. 163). The potential of these materials to be bonded to dentine as well as enamel has also contributed to the using of ceramic crowns in recent years (Ferrari M et al, 2000, p. 9B). With the development of new adhesive technologies in the last few decades, clinicians can maintain superior aesthetics when restoring maxillary anterior ETT (Teixeira ECN et al, 2006, p. 1006). All ceramic restorations of ETT in maxillary anterior teeth with GFPs showed excellent aesthetic and retention results as a good treatment option when restoring an ETT tooth with extensive loss of tooth structures after years (Öztürk E et al, 2011, p. 28).

An association between crown type and the survival of ETT was observed when the loss of tooth structure was questionable (Aquuillino \& Caplan, 2002, p. 258; Newman MP et al, 2003, p. 360). However, the type of failure of the bonded GFP demonstrated that they may protect the remaining tooth structure, particularly since the fracture occurs at the loads that rarely take place clinically (Paul \& Scharer, 1998, p. 513). The aim of this clinical study was to compare the clinical and the radiographic performance between different types of crowns and composite restoration. Those restorations were used for ETT in maxillary anterior teeth, after a glass-fibre post with composite resin core builds up.

\section{Subjects and methods}

All patients attended to the department of Endodontic and Prosthodontic for regular treatment in the Dental faculty. Jazan Universities were selected for this study. This study has been conducted after the agreement of the ethical committee in the faculty and signed consent form by all patients.

\subsection{Inclusion criteria for patients involved in this study}

1) All the cases were treated by graduated students at their last academic year.

2) Ages of the patients were between 17-25 years from both genders.

3) All the cases were ETT at maxillary anterior teeth and restored with GFP then composite resin core build up.

4) The quality of ETT should be RCT with no evidence of periapical pathology or root fracture. The periodontium was stable with no evidence of bleeding on probing and with a good bone support. All teeth should have enough ferrule and biological width, to allow the creation of the finish line on a sound tooth structure.

\subsection{Exclusion criteria's in this study}

1) Teeth with pulpal and periapical pathosis and those that could be used or diagnosed to be used as an abutment for prostheses.

2) Patients with absent from adequate posterior support and posterior vertical stops (absence of all molar teeth), or if there were any obvious occlusal interference or fremitus affecting the tooth to be restored.

A total of 50 maxillary anterior ETT were involved in this study. After RCTs of all teeth were finished, the roots were restored with reinforced GFPs (Relaxy Fiber Post, 3M ESPE, Germany), and composite resin cores (Tertic-N-Ceramic, Ivoclar Vivadent, Lichenestine). The 50 ETTs were divided into four groups depend on the crown type or the final restoration:

Group A consists of 10 ETT with GFP and composite restoration. Group B consists of 20 ETT with GFP and porcelain VITA VM (R) 9 (Vita Zahnfabric /Germany) fused to metal restoration. Group C consists of 10 ETT with GFP and e. max all ceramic (IPS e.max, Ivoclar/Vivadent) crowns.

Group D consists of 10 ETT with GFP and zirconia crowns, which consisted of a core's build up with Vita In-Ceram YZ Disc (Vita Zahnfabric/ Germany), and the porcelain build-up were done with porcelain VITA VM(R)9 (Vita Zahnfabric/Germany) crowns.

\subsection{Methods of fibre post preparation and cementation}

After the RCTs were done. The gutta-percha (GP) was removed to maintain a 4-5 mm apical seal. The canals were irrigated with a saline solution and sodium hypochlorite. The lengths of the posts in the canals were determined and marked, and the selected posts were placed into the canal to confirm its length. The canals were etched with $37 \%$ phosphoric acid for 15 seconds; the etch ant was rinsed with water and dried with paper points. Adhesive bonding agents were applied to the canal, and dual adhesive resin cements Rely X, TM. Unicem AppliCap Resin Cement (3M ESPE, Germany) was used for cementing of the posts, then light-cured for 60 seconds were applied. The cores were re-build up with composite resin in incremental techniques. All finish lines were on sound tooth structures.

\subsection{Methods of crowns preparation, fabrication and cementation}

Some of the composite cores with the remaining natural tooth structures were stayed in place, while others were prepared according to the type of the final restoration. Then the prepared areas were registered with addition silicon impression material using two steps technique and the shades were selected, metal and core try-in, and the final porcelain veneer layers were applied according to the selected shade guide. Finally, all the manufactured crowns were cemented. All the clinical and laboratory steps were done according to manufactures instructions.

\subsection{Post-operative evaluations}

All the cases were subjected to post-operative flow-up in form of clinical and radio-graphical evaluations after cementation of the crowns at periods of one week, 3, 6, and 12 months. All the restorations were evaluated by expert staffs who were not involved in the study or during the restoration (single -blind trial). The patients were educated about oral hygiene and motivated to use proper oral hygiene aids at the end of each treatment.

The evaluation of success or failure criteria's of the restorative tooth complex were judged to have failed if each post crown satisfied one or more of the following criteria presented in [table 1] over a period of 12 months:

Table 1: The Clinical and Radiographic Evaluation Criteria's of ETT

\begin{tabular}{c|l|l|}
$\begin{array}{c}\text { Restoration } \\
\text { type }\end{array}$ & Clinical examination of the restoration & Radiographic examination of the restoration \\
\hline Composite & Movement of crown margin under finger pressure & Caries at cervical margin \\
\hline PFM & Fracture of crown & Presence of periapical / /endodontic infection \\
\hline e.max & Loss of retention of the crown & Post fracture/ root fracture/crown fracture \\
\hline \multirow{2}{*}{ Zirconia } & De-bonding at post-core/ tooth interffaces & Loss of retention of the post \\
\cline { 2 - 2 } & Periodontal status/vilation of biological width & Post adaptation in the root canal \\
\cline { 2 - 2 } & Aesthetics (color changed) & \\
\cline { 2 - 2 } & Recurrent caries at crown margin & \\
\hline
\end{tabular}

\subsection{Statistical analyses}

All the data were recorded, and subjected to statistical analysis using statistical software SPSS (Statistical Package for the Social Sciences, IBM) version 21. The survival rates of the crowns were determined and compared during the different recall's periods using Kaplan - Meier analysis and log-rank test. The level of significance was set at $5 \%$.

\section{Results}

A total of 68 restorations were recruited to the study and 50 ETT which met the inclusion criteria were evaluated during this study. The majority of the restorations were PFM crown (20) while the other of restorations was 10 restorations for each (composite resin, e. max and zirconia). All the restorations were evaluated clinically 
and radiographic at the different periods one week of cementation, $3,6,9,12$ months respectively.

On the clinical assessment, the restorations in the four groups had no changes during one week; 3 and 6 months review [table 2]. While a movement of the crown margin under finger pressure was present in one case and loss or retention in 2 cases of zirconia. The periodontal status with violation of biological width was present in one case of PFM and finally the colour changes were obvious in one case of PFM and 2 cases of composite restoration during the follow-up review of 9 and 12 months. No clinical significant differences between the types of restoration at different time's intervals were detected [table 2].

Table 2: The Clinical Results of ETT at the Different Time Follow-Up

\begin{tabular}{|c|c|c|c|c|c|c|c|c|c|c|}
\hline \multirow[t]{2}{*}{ Criteria / time } & \multicolumn{2}{|c|}{ One week } & \multicolumn{2}{|c|}{3 months } & \multicolumn{2}{|c|}{6 months } & \multicolumn{2}{|c|}{9 months } & \multicolumn{2}{|c|}{12 months } \\
\hline & $\mathrm{N}$ & $\%$ & $\mathrm{~N}$ & $\%$ & $\mathrm{~N}$ & $\%$ & $\mathrm{~N}$ & $\%$ & $\mathrm{~N}$ & $\%$ \\
\hline \multicolumn{11}{|c|}{$\begin{array}{l}\text { vement of the crown margin under } \\
\text { finger pressure }\end{array}$} \\
\hline Composite & 10 & & 10 & (100) & 10 & (100) & 10 & (100) & & (100) \\
\hline PFM & 20 & (100) & 20 & $(100)$ & 20 & (100) & 20 & (100) & 20 & $(100)$ \\
\hline e max & 10 & (100) & 10 & (100) & 10 & (100) & 10 & (100) & 10 & $(100)$ \\
\hline Zirconia & 10 & (100) & 10 & (100) & 10 & (100) & 9 & (90) & 9 & (90) \\
\hline \multicolumn{11}{|c|}{ Fracture of the crown } \\
\hline Composite & 10 & $(100)$ & 10 & $(100)$ & 10 & (100) & 10 & (100) & 10 & $(100)$ \\
\hline PFM & 20 & (100) & 20 & $(100)$ & 20 & (100) & 20 & (100) & 20 & $(100)$ \\
\hline e max & 10 & (100) & 10 & (100) & 10 & (100) & 10 & (100) & 10 & (100) \\
\hline Zirconia & 10 & (100) & 10 & (100) & 10 & (100) & 10 & (100) & 10 & (100) \\
\hline \multicolumn{11}{|c|}{ Loss retention of the crown } \\
\hline Composite & 10 & (100) & 10 & (100) & 10 & (100) & 10 & (100) & 10 & $(100)$ \\
\hline PFM & 20 & (100) & 20 & $(100)$ & 20 & (100) & 20 & (100) & 20 & $(100)$ \\
\hline e max & 10 & (100) & 10 & (100) & 10 & (100) & 10 & (100) & 10 & (100) \\
\hline Zirconia & 10 & (100) & 10 & (100) & 10 & (100) & 8 & (80) & 8 & (80) \\
\hline \multicolumn{11}{|c|}{ onding at post-core/tooth interfaces } \\
\hline Composite & & & & & & & & & & \\
\hline PFM & 10 & (100) & 10 & $(100)$ & 10 & (100) & 10 & (100) & 10 & (100) \\
\hline e $\max$ & 20 & (100) & 20 & (100) & 20 & (100) & 20 & (100) & 20 & (100) \\
\hline Zirconia & 10 & (100) & 10 & (100) & 10 & (100) & 10 & (100) & 10 & (100) \\
\hline & 10 & (100) & 10 & (100) & 10 & (100) & 10 & (100) & 10 & (100) \\
\hline \multicolumn{11}{|c|}{$\begin{array}{l}\text { Jdontal status/violation of biological } \\
\text { width }\end{array}$} \\
\hline $\begin{array}{c}\text { width } \\
\text { Composite }\end{array}$ & & & & & & & & & & \\
\hline PFM & 20 & (100) & 20 & $(100)$ & 20 & (100) & 19 & (95) & 19 & (95) \\
\hline & 10 & (100) & 10 & $(100)$ & 10 & (100) & 10 & (100) & 10 & $(100)$ \\
\hline Zirconia & 10 & (100) & 10 & $(100)$ & 10 & (100) & 10 & (100) & 10 & (100) \\
\hline \multicolumn{11}{|l|}{ Aesthetic (color c } \\
\hline Composite & & (100) & 10 & $(100)$ & 10 & (100) & 8 & (80) & 8 & (90) \\
\hline & 20 & (100) & 20 & (100) & 20 & (100) & 19 & (95) & 19 & (95) \\
\hline e max & 10 & $(100)$ & 10 & $(100)$ & 10 & $(100)$ & 10 & $(100)$ & 10 & $(100)$ \\
\hline Zirconia & 10 & (100) & 10 & $(100)$ & 10 & (100) & 10 & (100) & 10 & $(100)$ \\
\hline \multicolumn{11}{|l|}{ Pecurrent caries at crov } \\
\hline Composite & & & 10 & $(100)$ & 10 & (100) & 10 & (100) & 10 & (100) \\
\hline & 20 & (100) & 20 & (100) & 20 & (100) & 20 & (100) & 20 & (100) \\
\hline e ma & 10 & $(100)$ & 10 & $(100)$ & 10 & $(100)$ & 10 & $(100)$ & 10 & (100) \\
\hline Zirconia & 10 & (100) & 10 & $(100)$ & 10 & (100) & 10 & $(100)$ & 10 & $(100)$ \\
\hline
\end{tabular}

The radiographic assessment for the restorations in the four groups had no changes during the one week, and 3 months review [table 3]. While during 6 months, a loosed of retention in one case of zirconia crown was detected, but during the 9 and 12-month reviews, two cases of recurrent caries at the cervical margin of the composite restoration, one case with presence of periapical infection were recorded. Finally, the Loss of retention of the post was recorded with one of the PFM restorations. No significant differences between the types of restoration at different time's intervals were detected by the radiographs [table 3].

Table 3: Radiographic Results of ETT at the Different Time Follow-Up

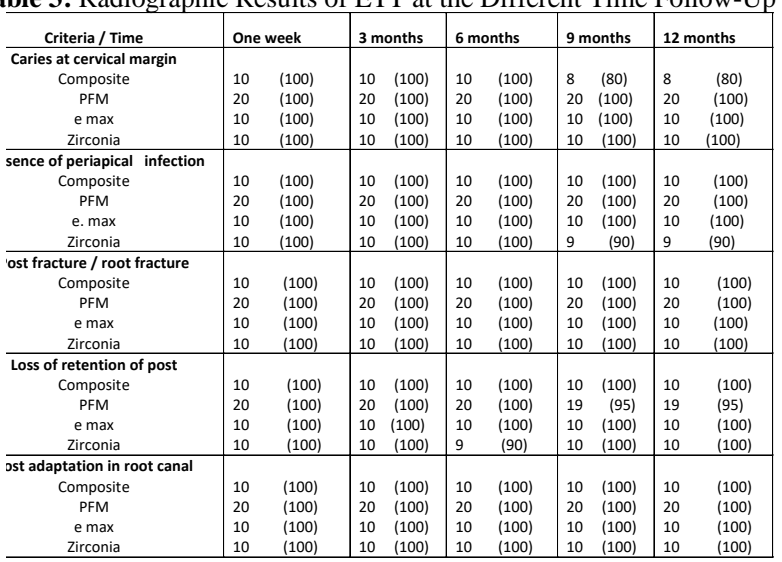

Overall survival at 12 months, the success rate in both clinical and radiographic examinations were $100 \%$ in terms of post, crown fractures or de-bonding from the tooth and post adaptation into the root canal. On other hand, the success rate was between $80-95 \%$ in terms of aesthetic, violation of biological width, periapical infection, secondary caries and presence of movement on pressure on the crown

\section{Discussion}

The present study was set out to test and compare the clinical performance of four types of restorations (composite resin, PFM, E max and Zircon), on maxillary anterior ETT teeth with glass fibre posts. GFPs are relatively new and becoming increasing popular in restoration of ETT in the maxillary aesthetic zone teeth.

From table $(2,3)$ after different periods of clinical and radiographic follow-up, the performance of GFP and composite restorations group was good and show excellent survival rates. This was in agreement with (Grandin S et al, 2005, p. 399; Preeth \& Kala, 2008, p. 162), those examined teeth restored with GFPs with direct composite restorations, which exhibited favourable clinical serves and results. Also we were totally agreed with Altun $\mathrm{C}$ et al, 2008 , p. 362, (17) about restoration of ETT with composite restoration after GFPs which recorded several advantages, such as an immediate aesthetic and functional rehabilitation, less time required and accepted by the patient.

Marginal discoloration of the composite resin restoration sometimes occurred, and their correction provided acceptable clinical results. There are many advantages of composite restorations; it is easy and familiar technique, cost-effectiveness and, it can be repolished after marginal discoloration (Yib KH et al, 2004, p. 350 (18). The colour changes and wear of the surfaces of composite restoration appeared at the 9 and 12 months recall, and were solved by the re-polishing of the restoration of the tooth or margin interferences.

The observed changes in the marginal fitting and the violation of the biological width of a restored tooth in the PFM group at 9 and 12 months recalls were recorded. This is in agreement with Preethi \& Kala, 2008, p. 162, who similarly observed minor differences in the marginal fit of teeth restored with these types of crowns. Always the marginal defect is mainly seen on the buccal surface of the tooth, while the palatal margin was intact.

In our study, the recurrent of caries was detected in two cases during the radiographic assessment of the composite restoration cases during 9 and 12 months recall (table 3 ). This could be due to the patient neglects and difficulty in practicing good oral hygiene. Furthermore, it could be due to the subgingival finish line place in this case. The composite restoration usually showed some surface wear of the composite, which is the predisposing reason for collection of bacteria in this area (Yib KH et al, 2004, p. 350 (18).

The clinical and radiographic performances of both e. max and zirconia all ceramic crowns over the 12 months period were good in the issues of aesthetic, colour stability, fractures of either crown or post, recurrent caries, this were close to the results of the study conducted by (Gemalmaz \& Ergin, 2002, p. 189; Etman \& Woolford 200, p. 80; Pradies G, 2015, p. 201; Taskonak \& Sertgöz, 2006, p. 1008). Additionally, the result of the present study was agreed with (Gemalmaz \& Ergin, 2002, p. 189), about the condition of the slight inflammation of the gingiva, in respective of the place of the finish line. From table 2, a case of zirconia showed a movement of the crown margin under finger presser of a crown and two cases with loss of retention during clinical recall examination at 9 and 12 months. These were corrected by the removal of the crowns and re-cement it after occlusal adjustment during different mandibular movement and premature occlusal adjustment. This is totally agreed with Preethi \& Kala 2008, p. 162; Öztürk E et al, 2011, P. 28), those shows similar results of movement of crowns under finger pressure at the 18 months recall of their cases. During the radiographic assessment, at an interval of 6,9 and 12 months (table 3 ), 2 cases showed a presence of periapical infection associated with zirconia crowns. This was strongly agreed with Ajayi DM et al, 2004, p. 58.

In our study, no clinical cases showed chipping or fractured of the restorative materials. This is in contrast with the finding of Rinke 
S et al, 2013; p. 228; Muhittin \& Sun 2015, p. 189, and those showed chipping of zirconia ceramic crown after 24, 36 months respectively. This could be related to the different survival time in the oral cavity.

The e. max crowns showed the best clinical and radiographic performances among the four groups. This is because of the physical and mechanical properties of the ceramic, such as biocompatibility, durability, radioactivity, flexure strength, and it does not pose any risk to the health of patients, dental technicians or dentists. Also if e.max CAD material is applied by the manufacturer's instructions, it does not show any toxic potential (Ivoclar V 2005, p. 1-16). Overall, the results of the present study were totally agreed with the results mentioned by Preeth \& Kala, 2008, p. 162; 1, Ferarri m et al, 2000, p. 9B; Texirea ECN et al, 2006, p. 1006; Ozurik K et al 2011; Newmen MP et al 2003, p. 360; Altun C et al 2008, p 350), (Gemalmaz \& Ergin, 2002, p. 189; Etman \& Woolford 200, p. 80) and Ajayi DM et al 2014, p. 58; Rinke S et al 2013, p. 228, in that, the ETT at the aesthetic zone can be restored with composite resin core for long temporary restoration, while all ceramic crowns can be used to replace the PFM restorations because of their better physical, mechanical and excellent biocompatible properties of the all ceramic materials.

In the light of the limitation of the present 12-month clinical and radiographic study design, a composite build-up can be used for ETT with GFP for long-temporary restoration under certain indications. Zirconia and e. max restorations showed promising results and appear to be an excellent alternative to the PFM restoration. Hoverer, long-term clinical and radiographic observation and assessment are required to authenticate this conclusion. The clinical success of those cases may be related to the education level of the patient in keep up high quality of oral hygiene. Also long-term study should be conducted.

\section{Conclusions}

From this study, over a period of 12 months, we can conclude that;

1) The success rate was $100 \%$ in terms of post, crown fractures or de-bonding from the tooth and post adaptation into the root canal. Eighty to $95 \%$ success rates were in terms of aesthetic, violation of biological width, peri-apical infection, recurrent caries and presence of movement on pressure of the crown in all groups.

2) E max and zirconia crowns have a higher success comparing to other groups. While PFM crowns and composite restorations were associated with colour changes and inflammation of the free gingiva.

3) Cases with loss of retention were re-cemented after correction of the causes of failure. While cases with colour changes were re-polished successfully.

4) No fractures or chipping cases in all groups were recorded.

\section{Acknowledgment}

This research was supported by a Grant Fund from the Deanship of Scientific Research, Future Scientists \# IV under number (FS4 036), College of Dentistry, Jazan University, Jazan, Saudi Arabia.

\section{References}

[1] Preethi GA, Kala M (2008). Clinical evaluation of carbon fiber reinforced carbon endodontic post, glass fiber reinforced post with cast post and core: A one year comparative clinical study. J Conser Dent; 11(4): 162-167. https://doi.org/10.4103/0972-0707.48841.

[2] Gutman JL (1992). The dentin-root complex: Anatomic and biological considerations in restoring endodontically treated teeth. J Prosthet Dent; 67: 458-67. $\underline{\text { https://doi.org/10.1016/0022- }}$ 3913(92)90073-J.

[3] Cohen BI, Pagnillo MK, Condos S et al (1996). Four materials measured for fracture strength in combination with five designs of endodontic posts. J Prosthet Dent; 76: 487-95. https://doi.org/10.1016/S0022-3913(96)90006-2.

[4] Sorenson JP, Martinoff JT (1983). Intracanal reinforcement and coronal coverage. A study of endodontically treated teeth. J Prosrhet Dent; 51; 780-84. https://doi.org/10.1016/00223913(84)90376-7.

[5] Paul S, Scharer P (1998). Post and core reconstruction for fixed prosthodontics restoration. Pract periodontics aesthet dent; 5; 513 20.

[6] Fuss Z, Lustig J, Katz A, Tamse A (2001). An evaluation of for endodontically treated vertical root fracture teeth: Impact of restorative procedures. J Endo; 27; 46-48 https://doi.org/10.1097/00004770-200101000-00017.

[7] King PA, Setchell DJ, Rees JS (2003). Clinical evaluation of a carbon fiber reinforced carbon endodontic post. J Oral Rehabil; 30: 785-789. https://doi.org/10.1046/j.1365-2842.2003.01178.x.

[8] Usumz A, Cobankara FK, Ozturk N, Eskitasciogku G, Belli S (2004). Microleakage of endodontically treated teeth with different dowel systems. J Prosthet Dent; 92:163-9. https://doi.org/10.1016/j.prosdent.2004.05.004

[9] Grandin S, Goracci C, Tay FR, Grandin R, Ferrari M (2005). Clinical Evaluation of the Use of Fiber Posts and Direct Resin Restoration for Endodontically Treated Teeth. Int J Prosthod; 18: 399-404.

[10] Trautmann G, Gutmann JL, Nunn ME, Witherspoon DE, Shulman JD (2000). Restoring teeth that are endodontically treated through existing crowns. Part II: Survey of restorative materials commonly used. Quintessence Int; 31: 719-28.

[11] Kato H, Matsumura H, Tanaka T, Atsuta M (1996). Bond strength and durability of porcelain bonding systems. J Prosthet Dent; 75: 163- 168. https://doi.org/10.1016/S0022-3913(96)90094-3.

[12] Ferrari M, Vichi A, Mannocci F, Mason PN (2000). Retrospective study of the clinical performance of fiber posts. Am J Dent; 13(Spec No): 9B-13B

[13] Teixeira ECN, Teixeira FB, Piasick JR, Thompson JY (2006). An in vitro assessment of prefabricated fiber post systems. JADA; 137 1006-1012. https://doi.org/10.14219/jada.archive.2006.0323.

[14] Öztürk E, Bolay S, Tuzgiray E, Baykara M. (2011), Esthetic Restoration Procedures for Endodontically Treated Anterior Roots. Clin Dent Research; 35(2): 28-34

[15] Aquuillino SA, Caplan DI (2002). Relationship between crown placement and the survival of endodontically treated teeth. J Prosth Dent; 37; 258-63

[16] Newman MP, Yaman P, Dennison J, Raffter M, Billy E (2003). Fracture resistance of endod-ontically treated teeth restored with composite posts. J Prosth Dent; 39; 360-7. https://doi.org/10.1067/mpr.2003.75.

[17] Altun C, Tozium TF, Guven G (2008). Multidisciplinary Approach to the Exhibition of a Crown Fracture with Glass-Fiber-Reinforced Composite: A Case report. JCDA; 74: 363-66.

[18] Yip KH, Smales RL, Kaidonis JA (2004). Differential wear of teeth and restorative materials: Clinical implication. Int J Prosthod; 17 350-56.

[19] Gemalmaz D, Ergin S (2002). Clinical evaluation of all ceramic crowns. J Prosthet Dent; 87: 189-96 https://doi.org/10.1067/mpr.2002.120653.

[20] Etman MK, Woolford MJ (2010). Three-year clinical evaluation of two ceramic systems: a preliminary study. J Prosthet Dent; 103: 8090. https://doi.org/10.1016/S0022-3913(10)60010-8.

[21] Pradíes G, Zarauz C, Valverde A, Ferreiroa A, Martínez-Rus F. (2015) Clinical evaluation comparing the fit of all-ceramic crowns obtained from silicone and digital intraoral impressions based on wave front sampling technology. J Dent; 43: 201-8 https://doi.org/10.1016/j.jdent.2014.12.007.

[22] Taskonak B, Sertgöz A (2006). Two-year clinical evaluation of lithia-disilicate-based all-ceramic crowns and fixed partial dentures. Dent Mater; 22: 1008-13. https://doi.org/10.1016/j.dental.2005.11.028.

[23] Ajayi DM, Oyekunle OOD, Gbadebo OS, Shaba PO (2014). Randomized clinical study comparing metallic and glass fiber post in restoration of endodontically treated teeth. Indi J Dent Rese; 25: 58 63. https://doi.org/10.4103/0970-9290.131126.

[24] Rinke S, Schäfer S, Lange K, Gersdorff N, Roediger M (2013). Practice-based clinical evaluation of metal-ceramic and zirconia molar crowns: 3-year results. J Oral Rehab; 40: 228-37. https://doi.org/10.1111/joor.12018.

[25] Muhittin T, Sun T (2015). Clinical evaluation of 121 lithium disilicate all-ceramic crowns up to 9 years. Quintessence International; 46: 189-97.

[26] Ivoclar Vivadent AG, Liechtenstein (2005). Scientific Documentation IPS e.max ${ }^{\circledR}$ CAD, Page 1-16. 